\title{
Advanced Test Reactor National Scientific User Facility (ATR NSUF) Monthly Report October 2014
}

Dan Ogden

October 2014

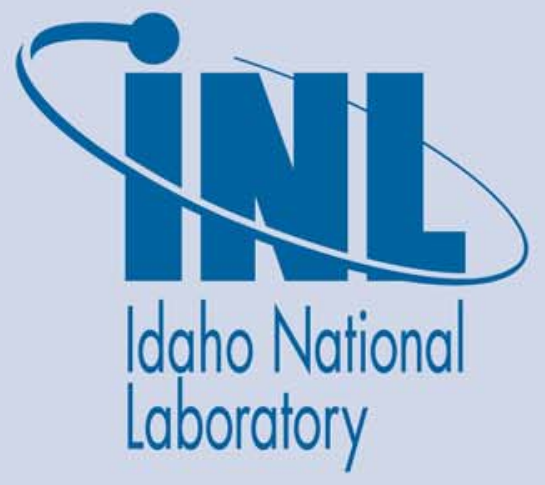

The INL is a U.S. Department of Energy National Laboratory operated by Battelle Energy Alliance 


\title{
Advanced Test Reactor National Scientific User Facility (ATR NSUF) Monthly Report October 2014
}

\author{
Dan Ogden
}

October 2014

\author{
Idaho National Laboratory \\ Idaho Falls, Idaho 83415
}

http://www.inl.gov

Prepared for the

U.S. Department of Energy

Office of Nuclear Energy

Under DOE Idaho Operations Office

Contract DE-AC07-05ID14517 


\title{
Advanced Test Reactor National Scientific User Facility (ATR NSUF) Monthly Report
}

\author{
October 2014
}

\section{Highlights}

- $\quad$ Rory Kennedy, Dan Ogden and Brenden Heidrich traveled to Germantown October 6-7, for a review of the Infrastructure Management mission with Shane Johnson, Mike Worley, Bradley Williams and Alison Hahn from NE-4 and Mary McCune from NE-3. Heidrich briefed the group on the project progress from July to October 2014 as well as the planned path forward for FY15.

- Jim Cole gave two invited university seminars at Ohio State University and University of Florida, providing an overview of NSUF including available capabilities and the process for accessing facilities through the peer reviewed proposal process.

- Jim Cole and Rory Kennedy co-chaired the NuMat meeting with Todd Allen. The meeting, sponsored by Elsevier publishing, was held in Clearwater, Florida, and is considered one of the premier nuclear fuels and materials conferences. Over 340 delegates attended with 160 oral and over 200 posters presented over 4 days.

- $\quad$ Thirty-one pre-applications were submitted for NSUF access through the NE-4 Combined Innovative Nuclear Research Funding Opportunity Announcement.

- $\quad$ Fourteen proposals were received for the NSUF Rapid Turnaround Experiment Summer 2014 call. Proposal evaluations are underway.

- John Jackson and Rory Kennedy attended the Nuclear Fuels Industry Research meeting. Jackson presented an overview of ongoing NSUF industry research.

\section{Milestones Completed}

- $\quad$ None

\section{Major Accomplishments/Activities}

\section{Awarded Research}

\section{Boise State University Rapid Turnaround Experiments (14-485 and 14-486)}

Nanoindentation and TEM work on the T91, HT9, HCM12A and 9Cr ODS specimens has been completed at CAES by Boise State PI Janelle Wharry and Cory Dolph. PI Corey Dolph will return in early November to complete their research by performing nanoindentation on unirradiated specimens that will be used as a baseline for their research. 


\section{North Carolina State University Rapid Turnaround Experiment (14-482)}

A new RTE for NCSU has been awarded for examination of nickel based specimens from the NCSU Acapsule. The scope of work for this experiment is similar to what was completed for Ahmad Alsabbagh, with plans to look at nano- and regular-grain specimens using TEM, XRD, microhardness and tensile testing. SEM will be used to examine the fracture surface of the tensile specimens. The student PI, David Woodley, has completed TEM and hardness analysis of both the nano and regular grain materials. Samples have been sent to the Analytical Lab for XRD analysis. The brittle nature of the nanograin material has complicated analysis efforts, particularly with tensile testing. David Woodley has sent non-irradiated specimens to MFC for analysis to provide a baseline for the data. Tensile specimens will be worked in FASB. The furnace has been removed from the load frame and is being readied for testing. SEM will be performed in FASB after testing is complete. Samples will be transferred to FASB once more detailed counting has been performed by the Analytical Lab. Completion of this work is pending restart of radiological work in EML and FASB.

\section{University of Illinois (12-355)}

13 tensile specimens have been prepared and loaded for shipment to APS. Only the specimens with a radiation exposure of $1 \mathrm{dpa}$ or less have dose rates $<5 \mathrm{mRem} / \mathrm{hr} @ 30 \mathrm{~cm}$, will be shipped, limiting the number of specimens available for testing in APS. The planned beam time at APS for April 10 was postponed until MRCAT resolved concerns over handling of the radioactive specimens. Cold testing has been performed by MRCAT and APS personnel. The new beam time has once again been delayed. The new date is expected in calendar year 2015. INL is ready to send the specimens as soon as authorization to ship is provided.

\section{Idaho State University MANTRA (09-197)}

Sample preparation on MANTRA 1 capsule specimens continued. Two shipments have been made to ATLAS to date. More shipments will be needed to complete MANTRA 1. Capsule 2 disassembly has been completed in HFEF and samples sent to Analytical Lab. The flux wires from Capsule 2 have been counted and provided to the PI for evaluation. Sample dissolution will begin once MANTRA 1 is complete. Completion of this work is pending restart of radiological work in the Analytical Lab.

\section{Drexel MAX (09-204)}

TEM and resistivity analysis of the TiAl and TiSiC specimens for capsules D, E and F has been completed. Eighteen specimens irradiated in the MIT reactor have been prepared and sent to CAES as well. Drexel PI Darin Tallman will return to CAES in November to perform FIB and TEM analysis on these MIT specimens (located at CAES). Darin will return to CAES throughout the fall and early winter, working toward completing his degree. Completion of this work is pending restart of radiological work in EML and FASB and the shipment of additional specimens from HFEF.

\section{Utah State University (09-157)}

The 18 USU specimens have been prepared and shipped to FASB for laser flash and DSC analysis (nine specimens for DSC and nine for laser flash). DSC analysis has been completed. Laser flash has yet to begin because of technical problems with the instrument. The instrument has been repaired and is available for analysis. In the interim, the nine DSC specimens and two of the laser flash specimens were transferred to the Analytical Lab for XRD analysis. XRD analysis has been completed and the specimens are ready to be sent back to FASB. Five additional specimens have been transferred from EML to FASB for SEM analysis. Sample preparation has been extensive and SEM analysis is ongoing. Completion of this work is pending restart of radiological work in EML and FASB and the shipment of additional specimens from HFEF. 


\section{University of Central Florida (UCF) (10-242)}

Analysis of the eight flux wire specimens has been completed by PNNL and data provided to the INL PI (Maria Okuniewski). Fourteen SiC specimens have been transfer from HFEF to EML. A decision will be made by the PI as to where to analyze these SiC specimens. TEM and foil specimens will be moved from HFEF to EML in the coming months. Completion of this work is pending restart of radiological work in EML and the shipment of additional specimens from HFEF.

\section{University of California, Berkeley (UCB) (10-244)}

PNNL initiated sectioning of Fuel Rodlet 1. Hydride redistribution measurement apparatus is complete.

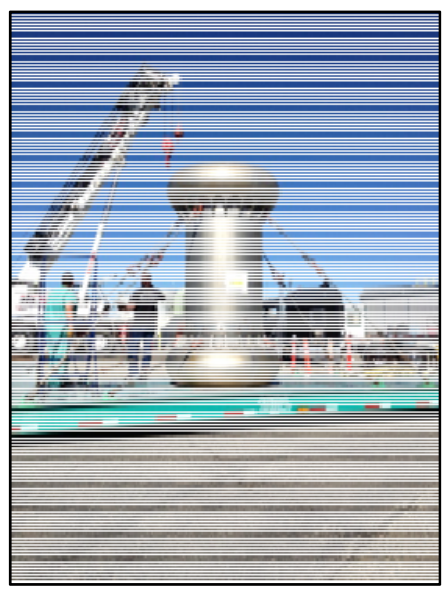

\section{University of California, Santa Barbara (USCB) (09-153)}

The University of California Santa Barbara 2 experiment was successfully sized in the ATR Dry Transfer Cubicle and shipped to HFEF in the GE-2000 cask.

\section{Cooperative Research}

Received parts to begin preparation of HFEF Instron for tensile testing. Initiated conversation with EPRI co-host and identified location and approximate timing of ANIAC meeting. Began preparation for maintenance of IASCC cells in preparation for the next set of tests for EPRI CRADA. Attended EPRI-NFIR meeting in Richland, Washington, and discussed path forward for EPRI ZG CRADA. Continued preparation of EPRI-1 capsule for irradiation in Loop 2A.

\section{Infrastructure Management}

Gap Analysis: The database continued to be populated with data from R\&D facilities. The Database Review Committee charter is in development. These activities will form the basis for the capabilities review for the gap analysis. Several scholarly papers were reviewed to aid in the identification of the direction of NE R\&D.

Database Review Committee: A draft charter for the DRC was written and forwarded to DOE-HQ for review. Their comments were incorporated and the charter is in the review process at NSUF.

Major NE R\&D Capabilities: The database continues to evolve. Additional facilities and instruments were added to the database from the initial university survey. A second survey is being developed to gather detailed information from all identified facilities.

\section{Upcoming Meetings/Events}

- $\quad$ Rory Kennedy, Donna Guillen and Sarah Robertson will attend the ANS Winter Meeting in Anaheim, California, November 9-12. 
- $\quad$ Mike Worley, manager of the Office of Innovative Nuclear Research (NE-42), will visit INL November 4-5.

- $\quad$ Rapid Turnaround Experiment awards from the summer 2014 call will be made prior to November 30 .

- The ATR NSUF program review meeting will be held December 9-10 at L'Enfant Plaza. In addition to NSUF staff and users, NE-4, NE-5 and NE-7 representatives will attend the meeting. 